\title{
Unifesp 25 anos - VR $360^{\circ}$
}

\author{
Leandro Key Higuchi Yanaze \\ Núcleo UAB-Unifesp \\ Universidade Federal de São Paulo \\ São Paulo, Brasil \\ leandro.yanaze@unifesp.br
}

\author{
Edna de Mello Silva \\ Núcleo UAB-Unifesp \\ Universidade Federal de São Paulo \\ São Paulo, Brasil \\ prof.ednamello@gmail.com
}

\author{
Marcelo de Paiva Guimarães \\ Núcleo UAB-Unifesp \\ Universidade Federal de São Paulo \\ São Paulo, Brasil \\ marcelo.paiva@unifesp.br
}

\begin{abstract}
Resumo-O "Unifesp 25 anos - VR 360" é um aplicativo de realidade virtual desenvolvido para fins de pesquisa aplicada que fez parte da campanha institucional comemorativa em 2019. O aplicativo buscou apresentar uma narrativa que remete ao passado, presente e futuro da Universidade Federal de São Paulo (Unifesp) de forma imersiva e interativa através de aplicativo desenvolvido para o dispositivo de Realidade Virtual Oculus Quest.
\end{abstract}

Palavras-chave - realidade virtual, campanha institucional, imersão, interatividade

\section{INTRODUÇÃO}

Em 2019 a Universidade Federal de São Paulo (Unifesp) celebrou 25 anos, instituição que nasceu com 80 anos. Ela foi criada a partir da expansão da Escola Paulista de Medicina (EPM), nascida em 1933 e situada na Vila Mariana em São Paulo. Atualmente, a Unifesp é formada por 7 campi distribuídos pelo estado de São Paulo. Ela oferece 55 cursos de graduação e atua em todas as áreas da ciência, além disso diversos cursos de pós-graduação e extensão. Faz parte também da universidade o Hospital São Paulo, que é um dos maiores e mais importantes hospitais do estado de São Paulo.

O aplicativo "Unifesp 25 anos - VR $360^{\circ}$ " foi criado para o dispositivo de Realidade Virtual Oculus Quest (https://www.oculus.com/quest/), com o objetivo de permitir a imersão em ambientes e vídeos $360^{\circ}$ e interação do usuário através de escolhas que realiza. Foi desenvolvido com a game engine Unity, aproveitando os diversos recursos já disponibilizados para a criação de aplicativos de Realidade Virtual.

O aplicativo é imersivo através de cenários, imagens e vídeos $360^{\circ}$ e a interação acontece pelos controles do Oculus Quest, para que o usuário consiga escolher as cenas e interagir com uma enquete.

Uma descrição mais detalhada sobre o aplicativo e suas implicações conceituais e científicas podem ser acessadas no capítulo "Desenvolvimento do Aplicativo Imersivo em Realidade Virtual e Vídeo $360^{\circ}$ 'Unifesp 25 Anos'" do livro Novos Meios, Novas Linguagens, Novos Mercados [1].

\section{OBJETIVos}

Desenvolvimento de um aplicativo imersivo e interativo em realidade virtual em alinhamento com a campanha institucional comemorativa dos 25 anos da Universidade Federal de São Paulo. Apresentar uma narrativa que mostra as bases da instituição (passado), informações atuais (presente) e compromisso com o desenvolvimento institucional (futuro). Possibilidade de desenvolver um aplicativo de realidade virtual com imagens e vídeos $360^{\circ}$ e interação do usuário para o dispositivo Oculus Quest. Disponibilizar o aplicativo durante a $5^{\text {a }}$ Semana Unifesp Mostra Sua Arte, que ocorreu entre 09 e 13 de setembro de 2019 em dois períodos e diferentes locais da Unifesp. Disponibilizar os vídeos $360^{\circ}$ do aplicativo em plataforma acessível.

\section{MAteriais E Métodos}

Para o desenvolvimento do aplicativo "Unifesp 25 anos VR $360^{\circ}$ ", foi utilizada a game engine Unity 2019.3 Personal, versão gratuita.

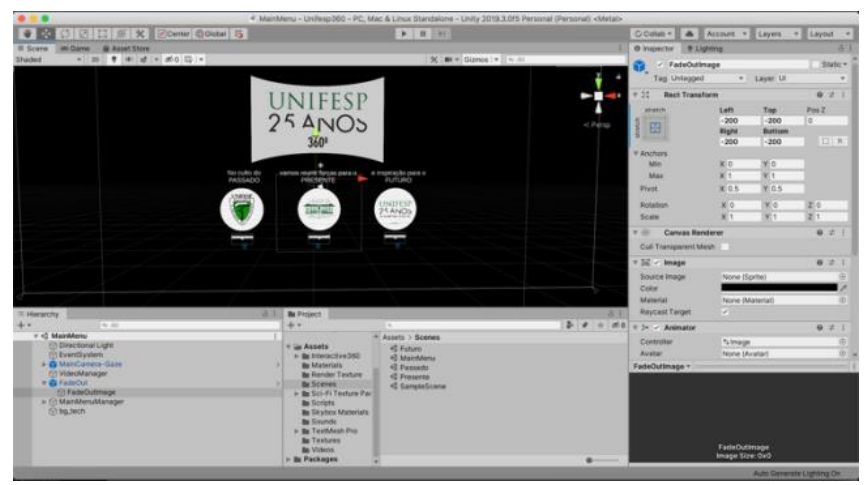

Fig. 1. Captura de tela do desenvolvimento do aplicativo em Unity

Para a composição da estrutura interativa de escolha de cenários e uso dos controles, partiu-se dos tutoriais "Getting Started With 360 Video" disponibilizados no canal de YouTube do Unity (https://www.youtube.com/watch? $\mathrm{v}=\mathrm{UroMw} 97 \mathrm{Wk} 6 \mathrm{Y} \&$ list= PLX2vGYjWbI0TifrTlupfrJeLa7c8LunUf). Acompanhando os tutoriais, foi utilizado o pacote de extensão "Interactive 360 Sample Project" contendo bibliotecas e scripts para a reprodução de vídeos $360^{\circ}$ disponibilizados gratuitamente na loja de recursos do Unity (https://assetstore.unity.com/packages/essentials/tutorialprojects/interactive-360-sample-project-108974).

O aplicativo se inicia com um menu inicial onde foram utilizados os logotipos da instituição, sendo o primeiro logotipo para remeter ao passado, o logotipo atual para remeter ao presente e o logotipo comemorativo da campanha de 25 anos da instituição para remeter ao futuro.

Os cenários do passado e do futuro são compostos por vídeos $360^{\circ}$ editados no software de edição e composição de vídeos Adobe Premiere $\mathrm{CC}$, em versão que já contém a funcionalidade de edição para vídeos $360^{\circ}$, com filtros e efeitos já otimizados para tal tipo de mídia. Tais vídeos $360^{\circ}$ podem ser armazenados e distribuídos em plataformas como YouTube e Facebook, que já estão adaptados para promover a visualização em dispositivos de realidade virtual e aproveitamento do giroscópio de smartphones se valendo da movimentação do espectador.

Para construir o cenário do passado, utilizou-se uma câmera $360^{\circ}$ para capturar a imagem de um saguão histórico da Unifesp. Depois, utilizou-se o software de edição e 
composição de imagens Adobe Photoshop CC para retirar digitalmente elementos modernos presentes no recinto e aplicar os filtros para dar o tom de envelhecimento. Da mesma forma, fotos históricas do acervo institucional (https://cehfi.unifesp.br/bmhv/imagens) foram selecionadas e tratadas para serem inseridas na narrativa. $\mathrm{O}$ ponto alto do cenário é projeção da versão editada do documentário restaurado pela Cinemateca Brasileira, intitulado "Escola de Médicos", de 1963, dirigida por Benedito Junqueira Duarte e produzida em comemoração aos 30 anos da Escola Paulista de Medicina, no formato de cinejornal.

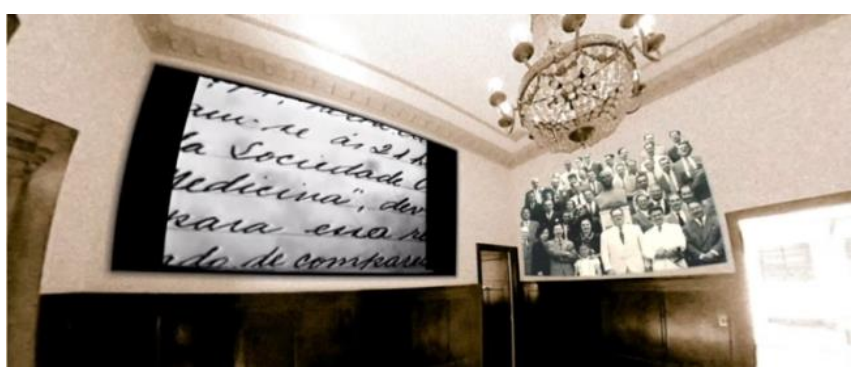

Fig. 2. Captura de tela do cenário do passado

Para a construção do cenário do presente, contou-se com o apoio de fotógrafo profissional que tem um drone, com o qual foi possível capturar fotos para a montagem de fotos $360^{\circ}$ dos campi da Unifesp, a saber: Campus São Paulo, Campus Baixada Santista, Campus Guarulhos, Campus Diadema, Campus São José dos Campos, Campus Osasco e Reitoria (nota dos autores: na ocasião, o Campus Zona Leste ainda não havia sido oficializado). Para cada campus, foram tiradas mais de 50 fotos com o drone DJI Mavic $360^{\circ}$. O conjunto de fotos foram tratados no software DJI Media Maker para comporem uma foto $360^{\circ}$. Essas dos campi foram editadas no Adobe Premiere CC, quando também foram adicionadas informações institucionais como quantidade de cursos, alunos, docentes e técnicos para apresentar um retrato de cada unidade acadêmica.

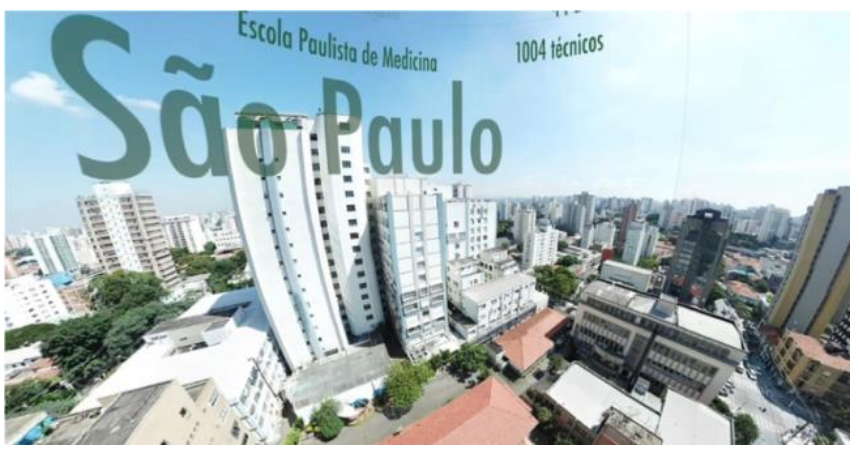

Fig. 3. Captura de tela do cenário do passado

Já o cenário do futuro, foi elaborado uma enquete para que o usuário votasse em um princípio institucional definido no pelo "Plano de Desenvolvimento Institucional da Unifesp 2016 - 2020" [2] Os princípios são: "Ética", "Democracia, transparência, equidade", "Qualidade e relevância", "Unidade e Diversidade" e "Sustentabilidade, bem viver social e ambiental". As respostas são armazenadas em um banco de dados MySQL e, logo após a escolha, o usuário tem acesso ao resultado geral de distribuição das escolhas dos usuários em um gráfico de barras e legenda percentual. A conexão para inserção e consulta das respostas no banco de dados é feita através de scripts em PHP colocadas em servidor WEB que são acionados pelo aplicativo no momento em que o usuário faz a sua escolha.

\section{RESUltados E Discuss ÃO}

Conforme previsto, o aplicativo foi apresentado durante a $5^{\text {a }}$ Semana Unifesp Mostra Sua Arte nos dias 09 de setembro de 2019 (Reitoria) e 10 de setembro de 2019 (Campus São Paulo), sendo disponibilizado o uso do dispositivo Oculus Quest de propriedade de um dos pesquisadores.

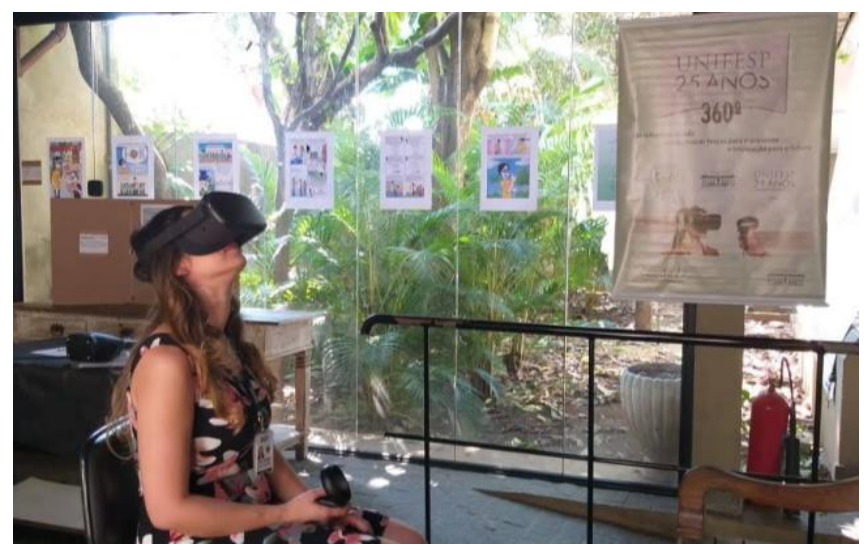

Fig. 4. Registro de usuária experimentando o aplicativo

Ao todo, foram contabilizadas 75 sessões, sendo que os seguintes dados foram adquiridos na enquete de escolha do princípio institucional para a construção da Unifesp do futuro:

TABELA I. RESULTADO DA ENQUETE SOBRE OS PRINCÍPIOS INSTITUCIONAIS PARA A UNIFESP DO FUTURO

\begin{tabular}{|c|c|c|}
\hline Princípios institucionais & Votos & $\%$ \\
\hline Ética & 22 & $29 \%$ \\
\hline Democracia, transparência e equidade & 19 & $25 \%$ \\
\hline Qualidade e relevância & 15 & $20 \%$ \\
\hline Unidade e diversidade & 10 & $13 \%$ \\
\hline $\begin{array}{l}\text { Sustentabilidade, bem viver social e } \\
\text { ambiental }\end{array}$ & 9 & $12 \%$ \\
\hline TOTAL & 75 & $100 \%$ \\
\hline
\end{tabular}

Os vídeos $360^{\circ}$ do aplicativo foram disponibilizados também no canal do YouTube da Unifesp, nos seguintes endereços:

1) Passado: https://www.youtube.com/watch?v=2xBPIZXnrE (191 visualizações em 03/09/2020).

2) Presente:

https://www.youtube.com/watch?v=NYheBgTTT6M visualizações em 03/09/2020).

\section{REFERENCES}

[1] YANAZE, L. K. H.; SILVA, E. M. (2019) . Desenvolvimento do Aplicativo Imersivo em Realidade Virtual e Vídeo $360^{\circ}$ ?Unifesp 25 Anos?. In: Alfredo Caminos; Anahí Lovato; Celia Retz Godoy dos Santos; Cristina Susigan; Danilo Bressan; Gabriela Coronel; Luiziane Saraiva; Tamara Guaraldo; Vicente Gosciola. (Org.). Novos Meios, Novas Linguagens, Novos Mercados. 1ed.Aveiro: Ria Editorial, 2019, v. , p. 267-285.

[2] UNIFESP. (2016). Plano de Desenvolvimento Institucional da Unifesp 2016 - 2020. 